\title{
Removal of Cd(II) from Phosphoric Acid Solution by Adsorbents: Equilibrium and Kinetic Studies
}

\author{
HAYET OMRI ${ }^{*}$ and NARJÈS HARROUCH BATIS
}

${ }^{a}$ Unity of Research of Elaboration of Nano-materials and their Applications, National institute of Applied Sciences and Technology, University of Carthage, North Urbain Centre B.T n 676-1080 Tunis Cedex -Tunisia

hayet.omri@yahoo.fr

Received 2 July 2012 / Accepted 28 July 2012

\begin{abstract}
The phosphoric acid obtained by wet-process is rich in impurities including heavy metals like cadmium. This work deals with the cadmium elimination from acid, by its adsorption on natural or modified clays and activated carbon, to improve its quality. The clays used in this study were effective for cadmium trapping from wet-phosphoric acid since it was reduced to approximately $80 \%$. Moreover, our study shows that the fixation of cadmium is proportional to the temperature which however cannot exceed $313 \mathrm{~K}$. On the other hand, the kinetic data, at the equilibrium, indicated that cadmium is more fixed on the inserted EDTA in the K10 montmorillonite (M). The kinetics of adsorption could be described by two models: pseudo-firstorder and pseudo-second-order, which depend on temperature and the nature of adsorbent. At different temperatures used and with various adsorbents viz., K10 Montmorillonite (M), Gross kaolinite (K), Activated carbon (C), EDTA inserted in K10 montmorillonite (MD), iron oxide inserted in K10 montmorillonite (MF) and Posidonia oceanica impregnated on kaolinite (KP), the pseudo second order model was the most reliable to determine the order of kinetics of adsorption of cadmium, which is also reflected a good correlation coefficient (above 0.97). The experimental equilibrium adsorption data of Cd(II) onto different adsorbents were in agreement with the Freundlich isotherm model.
\end{abstract}

Keywords: Phosphoric acid, K10-montmorillonite, Kaolinite, Cadmium, Kinetic, Equilibrium

\section{Introduction}

The phosphoric acid is obtained by wet-process from phosphate mineral $\left[\mathrm{Ca}_{3}\left(\mathrm{PO}_{4}\right)_{2}\right]$. It consists the reaction of phosphate with sulfuric acid. Although this process conducts to a rich acid in impurities, including metallic ions such as the cadmium which attracted much attention. The presence of this impurity affects the quantity and the quality of the product. For this reason, about 95\% of this acid produced by the wet-process is directly used as fertilizers and excluded from the use in non-fertilizer applications ${ }^{1}$. That's why, the elimination of cadmium from wet-process phosphoric acid is essential in order to obtain a product of better quality, of high added value with simultaneously a better protection of the environment and of the human being.

Many research techniques have been investigated for removal of cadmium from phosphoric acid, such as precipitation ${ }^{2-4}$, ion exchange ${ }^{5}$, solvent extraction ${ }^{6-8}$, ionic flotation ${ }^{9}$, membrane processes like electrodialysis, reverse osmosis and nanofiltration ${ }^{10-12}$, adsorption on activated carbon ${ }^{13-14}$, crystallization ${ }^{15}$, extraction with chelating or impregnated resins ${ }^{16-18}$ 
and concentration or addition of additives ${ }^{19}$. However, the uses of these techniques were limited due to a number of disadvantages such as high costs of organic solvents and resins (more often not regenerable), energy requirements, limited efficacy, the complicated process of treatment and also a risk of secondary pollution. To prevent and minimize these problems, recent studies have employed the use of low-cost adsorbents ${ }^{20}$.

In this work, we proposed to reduce the concentration of cadmium from wet process phosphoric acid by sorption onto clays which are modified by insertion or impregnation. In fact, clay minerals which are inexpensive have a large trapping capacity due, among other things, their best state of division ${ }^{21}$. To compare and highlight the results obtained with clays, we resorted to use a common adsorbent: activated carbon.

Two parameters were considered and varied such as the contact time between the clay and the adsorbate and the temperature of the treatment to determine their effect on the kinetics of adsorption and on the removal efficiencies of cadmium. Phosphoric acid that we have treated was supplied by the Tunisian Chemical Group (TCG).

\section{Experimental}

In this work, we used six types of adsorbent; kaolinite, kaolinite impregnated by posidonia oceanica, K10 montmorillonite, EDTA inserted in K10 montmorillonite, Iron oxide inserted in K10 montmorillonite and activated carbon. The choice of K10 montmorillonite and kaolinite is not fortuitous but their specific properties will be operated.

Kaolinite consists of leaves of silica tetrahedron and octahedron of alumina. These leaves form a compact layer, stable and insensitive to changes in physicochemical parameters $(\mathrm{pH}, \mathrm{T})$. For this, it was used as a support for the posidonia oceanica. The latter has great potential for retention of metals mainly the cadmium. In addition, the metal will be fixed on the membrane surface, which contains functional groups capable of retaining this metal ${ }^{22}$.

The K10 is a derivative of montmorillonite clay which is strongly activated by concentrated acid for the long time. It was used as a catalyst and/or adsorbent. Indeed, the acid-treatment causes the protonation and the delamination of the clay. Thereby, this conducts to a new type of mesoporous material having high surface area and high thermal stability. This allows easy insertion of large molecules between the layers of this clay ${ }^{23}$.

Ethylene diamine tetra-acetic acid (EDTA) is a hexadentate ligand. It forms strong complexes with most metal ions ${ }^{24}$. The complexation of cadmium by EDTA is shown in Figure 1.
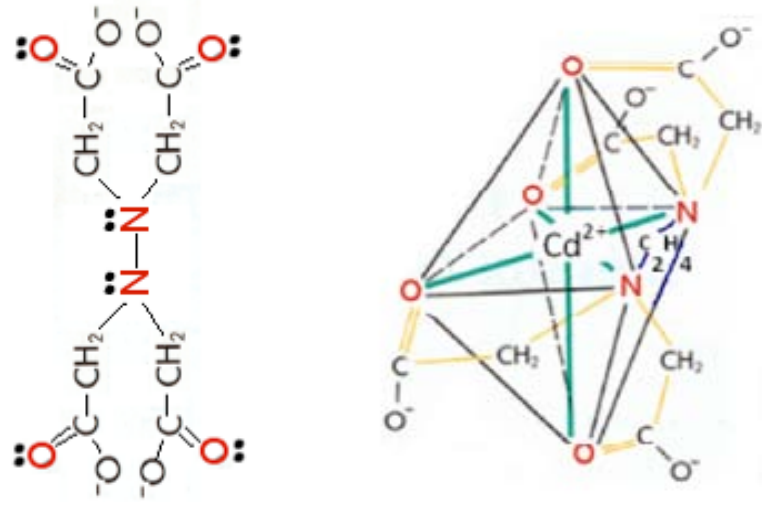

Figure 1. The complexation of Cd(II) with EDTA 
Iron oxide and alumina which are very abundant in the soil are known for their adsorptive properties next to the heavy metals ${ }^{25-30}$. They received special interest to modify the adsorptive properties of clays, by their introducing into interlayer spaces. This develops the contact surface and possibly promotes the nature's fixation sites of heavy metals.

The activated carbon is the most common adsorbent which is used for elimination the metal from the wet phosphoric acid. In our work, we used it in order to compare its retention capacity for the Cd with that obtained by clays ${ }^{13}$.

\section{Preparation of inserted or impregnated clays}

The preparation of inserted K10 montmorillonites requires a stage of intercalation; after the addition of the intercalating agent (iron polycations or EDTA) to a suspension of purified clay, the mixture was subjected to stirring for $24 \mathrm{~h}$. After centrifugation, the intercalated montmorillonite was washed several times then dried in an oven at $100{ }^{\circ} \mathrm{C}$ for $24 \mathrm{~h}$. Thus we obtained intercalated clay. The calcination in the furnace for $24 \mathrm{~h}$ gave us inserted clay. For the inserted montmorillonite by EDTA designated by MD, the calcination was performed at $200{ }^{\circ} \mathrm{C}$ and for insertion of iron oxide designed by MF, calcination was performed at $350^{\circ} \mathrm{C}$.

The impregnation of kaolinite was achieved by addition of $5 \mathrm{~g}$ of this clay to a suspension of Posidonia oceanica (2.5 g of posidonia finely crushed in $25 \mathrm{~mL}$ of distilled water) which was maintained under stirring for 30 minutes. The mixture thus obtained was stirred for an hour at a temperature of $100^{\circ} \mathrm{C}$. The resulting product was dried at $100{ }^{\circ} \mathrm{C}$ in an oven for $24 \mathrm{~h}$. This impregnated kaolinite is denoted by KP.

\section{Phosphoric acid}

The wet phosphoric acid which we were treated initially contains an amount equal to $51.65 \% \mathrm{P}_{2} \mathrm{O}_{5}$ and a quantity of cadmium equal to $15 \mathrm{mg} / \mathrm{L}$. For removal of cadmium from our acid we also used the activated carbon (C) to differentiate its adsorption capacity compared to clay.

\section{Methods}

\section{Characterisation of the sorbent}

In this study, the specific surface of clays used for the removal of cadmium was determined by using a Brunauer-Emmett-Teller (BET) nitrogen adsorption technique. Indeed, the different clays analyzed were first treated under vacuum for one hour at $150{ }^{\circ} \mathrm{C}$ to evacuate water and gas pore.

\section{Characterization of the phosphoric acid}

The content of cadmium in industrial phosphoric acid was measured by atomic absorption spectroscopy (AAS) in an air-acetylene flame at a wavelength of $228.8 \mathrm{~nm}$.

\section{Kinetic study}

In order to study the kinetic of cadmium adsorption at the different temperatures $\left(\mathrm{T}_{0}=300 \mathrm{~K}\right.$; $\mathrm{T}_{1}=313 \mathrm{~K}$ and $\mathrm{T}_{2}=333 \mathrm{~K}$ ) during $96 \mathrm{~h}, 0.5 \mathrm{~L}$ of solution of the wet-phosphoric acid was mixed with $2 \mathrm{~g}$ of adsorbent (K, M, MD, MF, KP or C).

To determine the instantaneous concentration of cadmium with time, we have done after each treatment time of several hours, a levy of a sample which was then analyzed by atomic 
absorption spectroscopy to determine the concentration of Cd. The fixed amount of cadmium per gram of adsorbent is given by the following equation:

$$
q_{t}=\left(C_{0}-C\right) \frac{v}{m}
$$

Where $\mathrm{q}_{\mathrm{t}}$ is the amount of cadmium adsorbed at various times (mg/g), $\mathrm{C}_{\mathrm{o}}$ and $\mathrm{C}$ are the initial and instantaneous concentrations of cadmium (mg/L) respectively, $\mathrm{V}$ is the volume of solution (L) and $\mathrm{m}$ is mass of adsorbent used (g). For model the kinetics of sorption of cadmium for the different sorbent materials tested, we used two different models from the literature. A pseudo-first-order kinetic model established by Lagergreen ${ }^{31}$ which is given by the following equation:

$$
\frac{d a}{d t}=k_{1}\left(q_{e}-q\right)
$$

With $\mathrm{k}_{1}$ is the rate constant of pseudo-first-order adsorption $\left(\mathrm{h}^{-1}\right)$, $\mathrm{q}$ is the amount of cadmium adsorbed at various times ( $\mathrm{mg} / \mathrm{g}$ ) and $\mathrm{q}_{\mathrm{e}}$ is the amount of cadmium adsorbed onto adsorbent at equilibrium (mg/g). After integrating with the initial condition, the equation becomes:

$$
\log \frac{q_{e}-q}{q_{e}}=k_{1} t
$$

The pseudo-second-order model is established by Ho and $\mathrm{McKay}^{32}$. It can be represented in the following form:

$$
\frac{d q}{d t}=k^{\prime}\left(q_{e}-q\right)_{2}
$$

Where $\mathrm{k}$, is the rate constant of pseudo-second-order model (g.mg $\left.{ }^{-1} / \mathrm{h}\right)$. After integrating with the initial condition, the form can be obtained as:

\section{Equilibrium study}

$$
\frac{t}{q}=\frac{1}{k^{\prime} q_{e}^{2}}+\frac{t}{q_{e}}
$$

The sorption isotherms express the specific relation between the concentration of sorbate and its degree of accumulation onto sorbent surface at constant temperature. In our study, the concentration of $\mathrm{Cd}(\mathrm{II})$ is fixed in $\mathrm{H}_{3} \mathrm{PO}_{4}$ solution to $15 \mathrm{mg} / \mathrm{L}$, it is necessary to vary the mass of adsorbent for represented the adsorption isotherms. The cadmium sorption capacity onto different modified clays have been tested by using the two-parameter Freundlich ${ }^{33}$ and Langmuir ${ }^{34}$ isotherm equations.

Freundlich $^{33}$;

Langmuir $^{34}$;

$$
\begin{gathered}
\mathrm{q}_{\mathrm{e}}=\mathrm{K}_{\mathrm{f}} \mathrm{C}_{\mathrm{e}}^{1 / \mathrm{n}} \\
q_{e}=\frac{q_{m} K_{L} C_{e}}{1+K_{L} C_{e}}
\end{gathered}
$$

With $\mathrm{q}_{\mathrm{e}}$ : the equilibrium adsorption capacity $\mathrm{mg} / \mathrm{g}, \mathrm{C}_{\mathrm{e}}$ : the equilibrium concentration of cadmium in solution $(\mathrm{mg} / \mathrm{L}), \mathrm{K}_{\mathrm{f}}$ : a measure of adsorption capacity, $1 / \mathrm{n}$ : the adsorption intensity, $\mathrm{K}_{\mathrm{L}}$ : the Langmuir adsorption constant, $\mathrm{q}_{\mathrm{m}}$ : the sorption capacity, or the amount of adsorbate at complete monolayer coverage (mg/g). The Freundlich isotherm is valid for a heterogeneous adsorbent surface with a non-uniform distribution of heat of adsorption over the surface. The Langmuir isotherm, however, assumes that the sorption takes place at specific homogeneous sites within the adsorbent. 


\section{Results and Discussion}

\section{Specific surfaces of the adsorbents}

In this study, the surface area of these adsorbents was performed so that it could help in the interpretation of the results of the kinetic and adsorption studies. Their values are presented in Table 1.

Table 1. Specific surfaces $\left(\mathrm{S}_{\mathrm{BET}}\right)$ of simples used

\begin{tabular}{ll}
\hline \multicolumn{1}{c}{ Nature of Clay } & \multicolumn{1}{c}{$\mathrm{S}_{\mathrm{BET}}, \mathrm{m}^{2} / \mathrm{g}$} \\
\hline K10 Montmorillonite (M) & 142 \\
K10 montmorillonite modified by EDTA (MD) & 204 \\
K10 montmorillonite modified by iron oxide (MF) & 290 \\
Gross kaolinite (K) & 11 \\
Posidonia oceanica impregnated kaolinite (KP) & 13 \\
Actived carbon (C) & 1200 \\
\hline
\end{tabular}

As seen in Table 1, the materials formed by K10 montmoillonite present the highest specific surface. This result is due to the delamination, essentially due to the porous system that creates an interlayer space of the clay. Indeed, the highest specific surface $\left(290 \mathrm{~m}^{2} / \mathrm{g}\right)$ is obtained in the case of the inserted clay with iron oxide. This is likely due to the insertion of a greater number of polycation and perhaps, a more homogeneous repartition, which conducts to a bigger number of pores, hence a higher specific surface.

\section{Reduction of cadmium from phosphoric acid}

The concentrations of cadmium in the phosphoric acid before and after treatment are given in Table 2. From this table, we noticed that at $\mathrm{T}_{0}$ the modified adsorbents (MD, FM and KP) are more effective for the adsorption of cadmium. For that reason, we worked in the following by the modified adsorbents (by varying the time to contact and the temperature). Even though the activated carbon has the highest specific surface $\left(1200 \mathrm{~m}^{2} / \mathrm{g}\right)$, the amount of cadmium which is set by this adsorbent is not the greatest. This is probably due to the nature and specificity of the sites for retains this metal. Indeed, K10 montmorillonite seems to be endowed with a higher number of specific sites, which probably favor the more important retention.

Table 2. The concentrations of cadmium in the phosphoric acid before and after treatment

\begin{tabular}{cccccccc}
\hline Nature of the adsorbent & M & K & C & MD & MF & KP \\
\hline \multirow{2}{*}[\mathrm{Cd}]{$_{\text {initial }}$, ppm } & & 15,08 & 15,08 & 15,08 & 15,08 & 15,08 & 15,08 \\
& T0 & 9,72 & 12,35 & 12,04 & 4,26 & 9,35 & 10,74 \\
{$[\mathrm{Cd}]_{\text {final }}$, ppm } & T1 & - & - & - & 3,16 & 7,45 & 6,40 \\
& T2 & - & - & - & 10,93 & 11,98 & 12,09 \\
\hline
\end{tabular}

We suggest that even though the specific retention cadmium sites are present on the active carbon, their number is three times as big on the montmorillonite. Kaolinite has the lowest specific surface even with its modification by impregnation. Indeed, by using the posidonia as impregnating agent, the amount of cadmium removal by this adsorbent is very important (57\%). In fact, some studies ${ }^{23,35}$, have shown that posidonia has great potential for retention of metals mainly cadmium. In addition, the bulk of this metal seems to be fixed on the membrane surface, which contains functional groups like (-NH...) capable of retaining them.

The number of active sites available on the surface of the adsorbent material after modification has probably become more important which can justifies the increase in the amount of cadmium retained.

\section{Effect of adsorbent dosage (w)}

In order to fix the optimum dosage decadmiation, experiments were carried out with various dosages of adsorbent ranging from 3.0 to $4.4 \mathrm{~g}$ with $15 \mathrm{mg} / \mathrm{L}$ as initial cadmium concentration and the results were given in Figure 2. 


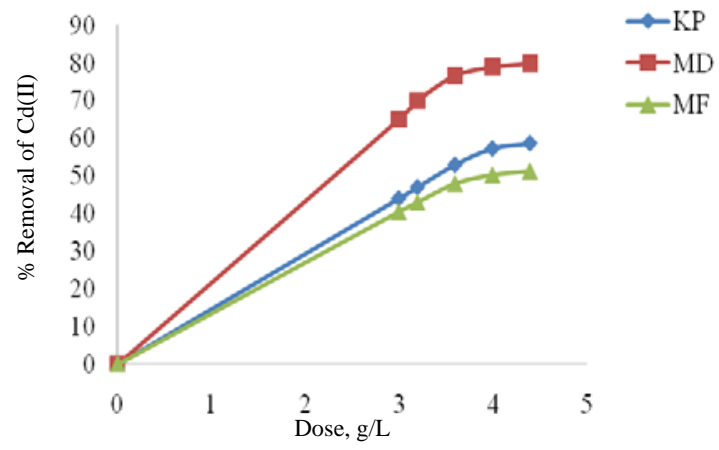

Figure 2. Effect of adsorbent dose on the removal of $\mathrm{Cd}(\mathrm{II})$ by different modified clays $\mathrm{T}=313 \mathrm{~K}, \mathrm{t}=96 \mathrm{~h}, \mathrm{Co}=15 \mathrm{mg} / \mathrm{L}$

As it is obvious, the percent cadmium removal increases with increase in the dose of the sorbent due to more active sites with an increase in amount of sorbent ${ }^{36}$. The optimum dosage was fixed as $2.0 \mathrm{~g}$ for further studies as this dosage found to bring down the level of cadmium within the tolerance limit.

\section{Effect of contact time}

Moreover, the cadmium quantity removed depends on different parameters such as contact time and the temperature of the treatment. Figure 3 and 4 present the plot of the amount of cadmium adsorbed $(\mathrm{mg} / \mathrm{g})$ a function of the time at different temperatures.

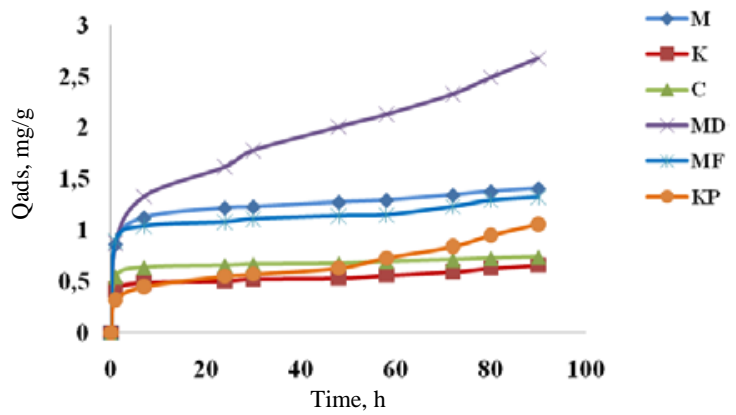

Figure 3. The sorbed amount of Cd(II) on various adsorbents according to treatment time at $\mathrm{T}_{0}$.
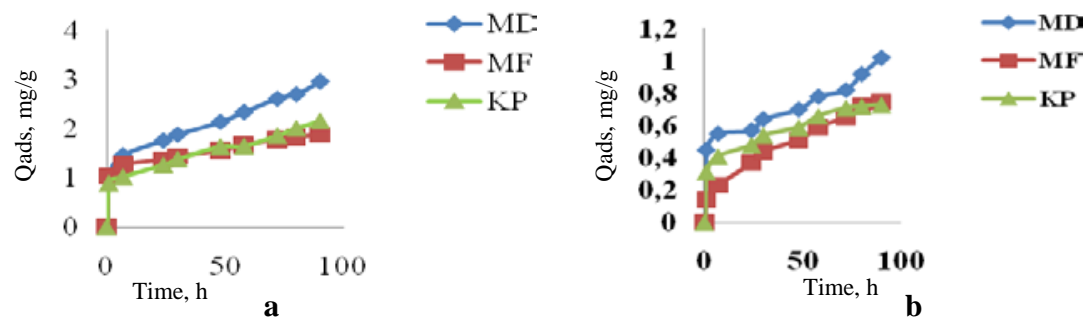

Figure 4. The sorbed amount of $\mathrm{Cd}(\mathrm{II})$ on various adsorbents at different temperatures according to treatment time: (a) at $\mathrm{T}_{1}$ and (b) at $\mathrm{T}_{2}$

The adsorption kinetics of cadmium on various adsorbents (M, K, C, MD and KP MF) at different temperatures has almost the same speed. Furthermore, the curves show more than one linear region. An initial steep portion attributed to the diffusion of adsorbate through the solution to the external surface of the adsorbent. This stage is characterized by a strong adsorption in the 
early hours of contact. This is obvious from the fact that a large number of vacant surface sites are available for adsorption during this initial stage.

A second portion describes the gradual adsorption stage, which is characterized by a slow adsorption. One can easily see that the modified clays MF and KP can eliminate almost the same rate of cadmium. The inserted montmorillonite by EDTA has the best retention of this impurity. In this stage, the remaining vacant sites on surface are difficult to be occupied due to repulsive forces between the solute molecules on the solid ${ }^{37}$. The third portion is attributed to the final equilibrium stage where adsorption is very slow due to extremely low adsorbate concentration in solution ${ }^{38,39}$.

We also note that the elimination of cadmium is proportional to temperature. However, for a very high temperature, the retention rate of cadmium is low, which indicates an optimum temperature for the elimination of this metal.

\section{Kinetic study}

The kinetics of the adsorption process was analyzed using the pseudo-first-order and pseudo-second-order equations, to model the kinetics cadmium adsorption onto various adsorbents at different temperatures. For each adsorbent we plotted the two kinetic models, which are given in the Figures 5-8.
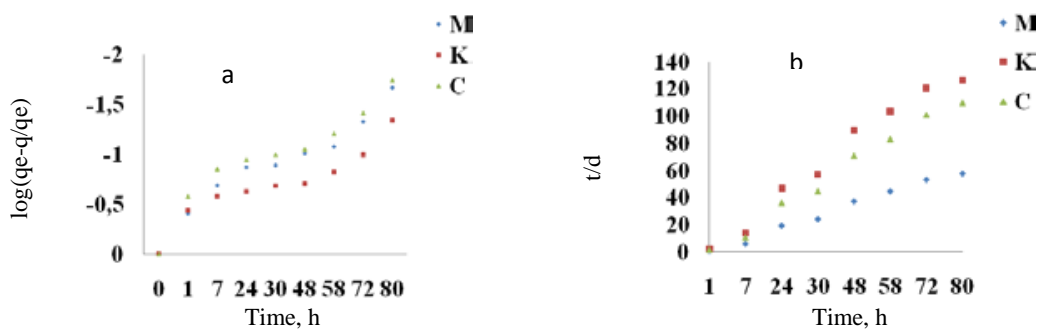

Figure 5. Kinetic models for adsorption of $\mathrm{Cd}(\mathrm{II})$ on $\mathrm{M}, \mathrm{K}$ and $\mathrm{C}$ at $\mathrm{T}_{0}$ : (a) Pseudo-first order and (b) Pseudo-second order
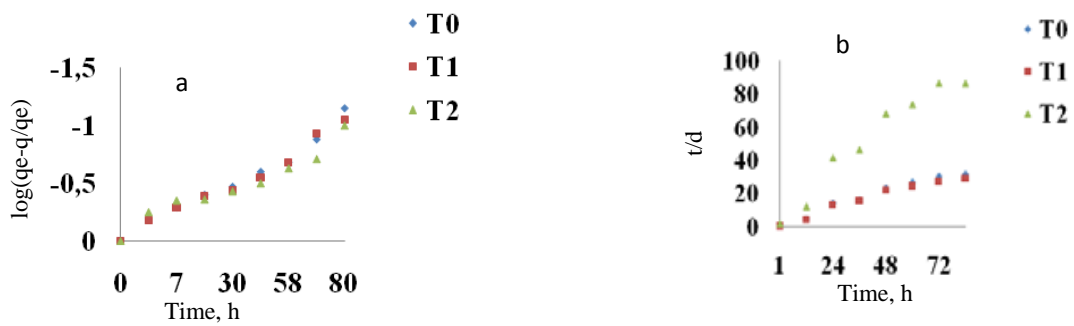

Figure 6. Kinetic models for adsorption of Cd(II) on MD: (a) Pseudo-first order and (b) Pseudo-second order
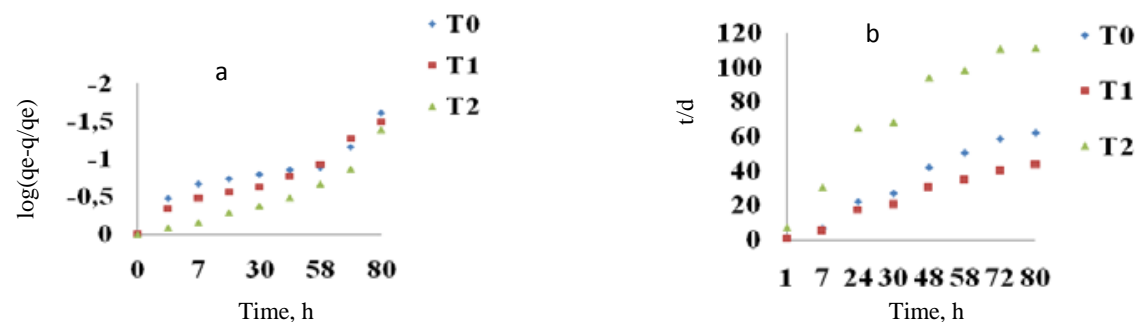

Figure 7. Kinetic models for adsorption of Cd(II) on MF: (a) Pseudo-first order and (b) Pseudo-second order 

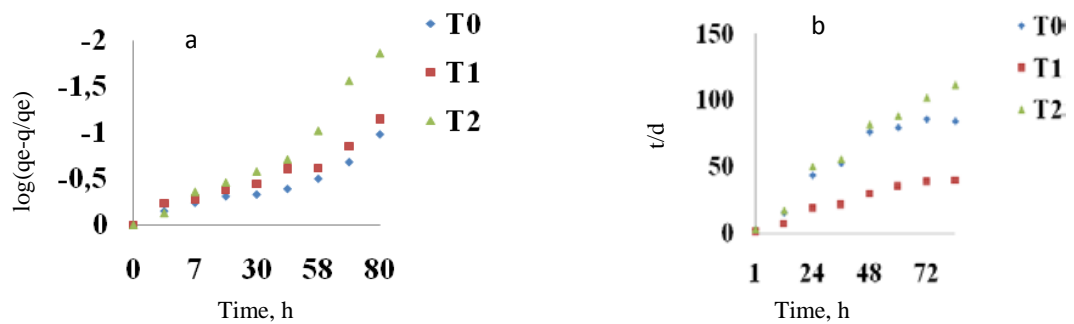

Figure 8. Kinetic models for adsorption of Cd(II) on KP: (a) Pseudo-first order and (b) Pseudo-second order

Kinetics parameters for cadmium onto various adsorbents and at different temperatures are presented in Table 3. Slopes and intercepts of plots of $\log \frac{q_{e}-q}{q_{e}} v s$. t were obtained for cadmium to determine the first-order rate constant $\mathrm{k}_{1}$. Indeed, the correlation coefficients for the first-order kinetic model at different temperatures for various adsorbents were relatively low. The pseudo-second-order rate constant $\mathrm{k}^{\prime}$ and equilibrium adsorption amount $\mathrm{q}_{\mathrm{e}}$ were determined from the slopes and intercepts of plots of $\frac{t}{q}$ vs. t. The correlation coefficients for the pseudo-seond-order kinetic model at different temperatures were above 0 , 96 . In fact, the high correlation coefficients $\left(\mathrm{R}^{2}>0,96\right.$ in most cases) demonstrated that the adsorption kinetic of cadmium followed the pseudo-second-order (Table 3).

Table 3. Kinetics parameters for Cd(II) at different temperatures

\begin{tabular}{|c|c|c|c|c|c|c|c|}
\hline \multirow[b]{2}{*}{$\mathrm{T}, \mathrm{K}$} & \multirow[b]{2}{*}{ Adsorbents } & \multicolumn{3}{|c|}{ Pseudo-first order kinetics } & \multicolumn{3}{|c|}{ Pseudo-second order kinetics } \\
\hline & & $\mathrm{q}_{\mathrm{e}} \mathrm{mg} \mathrm{g}^{-1}$ & $\mathrm{k}_{1}, \mathrm{~h}^{-1}$ & $\mathrm{R}^{2}$ & $\begin{array}{c}\mathrm{q}_{\mathrm{e}} \\
\mathrm{mg} \cdot \mathrm{g}^{-1}\end{array}$ & $\begin{array}{c}\mathrm{k}^{\prime} \\
\text { g.h } \mathrm{h}^{-1} \cdot \mathrm{mg}^{-1}\end{array}$ & $\mathrm{R}^{2}$ \\
\hline \multirow{6}{*}{300} & MD & 2,68 & 0,127 & 0,966 & 0,216 & 11,749 & 0,9649 \\
\hline & MF & 1,32 & 0,151 & 0,873 & 0,107 & 10,548 & 0,9823 \\
\hline & KP & 1,06 & 0,102 & 0,907 & 0,080 & 13,507 & 0,9073 \\
\hline & M & 1,41 & 0,173 & 0,898 & 0,116 & 9,198 & 0,9889 \\
\hline & K & 0,66 & 0,126 & 0,883 & 0,052 & 23,339 & 0,9775 \\
\hline & $\mathrm{C}$ & 0,74 & 0,172 & 0,934 & 0,061 & 16,626 & 0,9889 \\
\hline \multirow{3}{*}{313} & MD & 2,96 & 0,123 & 0,974 & 0,237 & 11,714 & 0,9612 \\
\hline & MF & 1,88 & 0,164 & 0,954 & 0,156 & 9,301 & 0,9797 \\
\hline & KP & 2,15 & 0,123 & 0,942 & 0,172 & 15,84 & 0,9595 \\
\hline \multirow{3}{*}{333} & MD & 1,02 & 0,101 & 0,930 & 0,077 & 30,728 & 0,9481 \\
\hline & MF & 0,75 & 0,152 & 0,896 & 0,067 & 38,25 & 0,9199 \\
\hline & KP & 0,73 & 0,102 & 0,928 & 0,064 & 34,703 & 0,9683 \\
\hline
\end{tabular}

So we can conclude that the pseudo second order model is more reliable to determine the order of kinetics of adsorption of cadmium by various adsorbents $(\mathrm{M}, \mathrm{K}, \mathrm{C}, \mathrm{MD}, \mathrm{MF}$ and $\mathrm{KP}$ ), which is reflected by a good correlation coefficient implying a mechanism of chemisorption type adsorption. Therefore, the reaction brought into play when fixation of the cadmium on these adsorbents at different temperatures is pseudo-second order.

This suggests a probable chemisorption, which are the result of any shares or exchange of electrons between the impurities phosphoric acid such as the cadmium and the functional groups of these adsorbents. 


\section{Adsorption isotherms}

The experimental equilibrium adsorption data of $\mathrm{Cd}(\mathrm{II})$ adsorption onto different modified clays have been tested by using Freundlich and Langmuir isotherm equations. The Freundlich isotherm is valid for a heterogeneous adsorbent surface with a non-uniform distribution of heat of adsorption over the surface. The Langmuir isotherm, however, assumes that the sorption takes place at specific homogeneous sites within the adsorbent.

The parameters of the isotherm and the correlation coefficient, $\mathrm{R}^{2}$ for the fitting of the experimental data are listed in Table 4. By comparing the results of the values for the correlation coefficients, it was found that the Freundlich isotherm generally represent the equilibrium sorption of Cd(II) onto different modified clays.

Table 4. Isotherm parameters for Cd(II) adsorption onto different modified clays

\begin{tabular}{lccc}
\hline Freundlich & & & \\
\hline Adsorbent & $\mathrm{K}_{\mathrm{f}}\left[(\mathrm{mg} / \mathrm{g})(\mathrm{mg} / \mathrm{L})^{1 / \mathrm{n}}\right]$ & $1 / \mathrm{n}$ & $\mathrm{R}^{2}$ \\
$\mathrm{KP}$ & 2,02 & 0,0954 & 0,9841 \\
MD & 2,68 & 0,0696 & 0,9935 \\
MF & 1,735 & 0,0765 & 0,9831 \\
Langmuir & & & \\
Adsorbent & $\mathrm{K}_{\mathrm{L}}, 1 / \mathrm{mg}$ & $\mathrm{q}_{\mathrm{m}}, \mathrm{mg} / \mathrm{g}$ & $\mathrm{R}^{2}$ \\
KP & 0,077 & 4,798 & 0,9681 \\
MD & 0,155 & 7,535 & 0,876 \\
MF & 0,0197 & 12,97 & 0,8635 \\
\hline
\end{tabular}

\section{Conclusion}

In this work, the low-cost adsorbents (clays) which have high capacities in adsorption of cadmium ions from wet-phosphoric acid were used in their natural or modified form. For the removal of cadmium from the acid, the activated carbon was also used to differentiate its adsorption capacity compared to clay.

From our data, it can be shown that for the activated carbon which has the highest specific surface $\left(1200 \mathrm{~m}^{2} / \mathrm{g}\right)$, the amount of cadmium set by this adsorbent is not the greatest. Moreover, the modified clays seem to be effective and economical adsorbent for the removal of cadmium. Indeed, this adsorption depends to the temperature, so that the removal efficiency increases with a slight increase in the temperature. But when the temperature is relatively high, the adsorption rate increases slowly. Therefore, we can observe that there is an optimum temperature not to exceed for the adsorption of cadmium on these modified clays (MD, FM and KP). By comparing the adsorption on the different clays, we note that the inserted montmorillonite with EDTA is the best adsorbent of cadmium. Indeed, we can note that the best adsorption of cadmium from wetphosphoric acid, is recommended at a temperature less than or equal to $313 \mathrm{~K}$ and on the EDTA inserted in K10 montmorillonite. The kinetics study of adsorption also showed that the model of pseudo-second order is best suited to describe the kinetics of adsorption of cadmium on different types of adsorbents at different temperatures, thus implying an adsorption mechanism of chemisorption type. The equilibrium Study showed that the Freundlich isotherms well represent the equilibrium adsorption of Cd(II) onto different modified clays.

\section{References}

1. Kotz J C and Purcell K F, Uses of Phosphate Containing Rock Chemistry and Chemical Reactivity; $2^{\text {nd }}$ Ed., McGraw-Hill, Tokyo, Japan, 1991. 
2. Ennaassia E T, El Kacemi K, Kossir A and Cote G, Hydrometallurgy, 2002, 64(2), 101-109.

3. Kijkowska R, Pawlowska-Kozinska D, Kowalski Z, Jodko M and Wzorek Z, Sep Purif Technol., 2002, 28, 197-205.

4. El-Asmya A A, Serag M H, Mahdyb A M and Amin I M, Sep Purif Technol., 2008, 61, 287-292.

5. Koopman C, Witkamp G J and Van Rosmalen G M, Sep Scie Techn., 1999, 34, 2997-3008.

6. $\quad$ Elyahyaoui A and Bouhlassa S, App Rad Isotop., 2001, 54(6), 921-926.

7. $\quad$ Nazari K, Maragheh M G and Rad A J, Hydrometallurgy, 2004, 71, 371-377.

8. $\quad$ Chehid E M B, Amor M B and Pourcelly G, Sep Purif Technol., 2006, 51, 285-290.

9. $\quad$ Bessière J, Bruant M, Jdid E A and Blazy P, Int J Miner Process, 1986, 16, 63-74.

10. Qafas E E Z, El-Kacemi K and Edelahi M C, Sci Lett., 2001, 3, 3.

11. Koopman C and Witkamp G J, Sep Sci Technol., 2002, 37, 1273-1290.

12. Essis-Tome H, Diawara C K, Robbiola L, Cote G, Kossir A, El Kacemi K, Qafas Z and Pontié M, Electrochem Commun., 2004, 6(10), 1061-1068.

13. Monser L, Ben Amor M and Ksibi M, Chem Eng Process, 1999, 38, 267-271.

14. Rangel-Mendez J R. and Streat M, Water Res., 2002, 36, 1244-1252.

15. Toye D, Schlitz M and Crine M, La Tribune de l'eau, 1993, 46, 11-18.

16. Booker N A and Streat $\mathrm{M}$, Proceedings of Ion Exchange for Industry, Imperial College, In: Streat M (Ed)., London, 1988, 632.

17. Kabay N, Demircioglu M, Ekinci H, Yüksel M, Saglam M, Akçay M and Streat M, Ind Eng Chem Res., 1998a, 37, 2541-2547.

18. Kabay N, Demircioglu M, Ekinci H, Yüksel M, Saglam M, Akçay M and Streat M, React Funct Polym., 1998b, 38(2-3), 219-226.

19. Suzuki T, Hatsushika T and Hayakawa Y, Faraday Trans., 1980, 77, 1059-1062.

20. Babel S and Kurniawan T A, J Hazard Mater., 2003, B97, 219-243.

21. Bailey S E, Olin T J, Bricka R M and Adrian D D, Water Res., 1999, 33, 2469-2479.

22. Pasqualini V, Pergent-Martini C and Pergent G, Int J Environ Pollut., 2000, 13, 126-147.

23. Philip J W, Will P G, Antonio F P, Janet L S and Euneace T, Green Chem., 2007, 9, 980-986.

24. Koji S and Hiroyuki S, Biotechnol Lett., 1994, 16, 455-460.

25. Forbes E A, Posner A M and Quirk J P, J Soil Sci., 1976, 27(2), 154-166.

26. Benjamine M M and Leckie J O, J Coll Inter Sci., 1981, 79, 209-221.

27. Rudin M and Motschi H, J Coll Inter Sci., 1984, 98, 385-393.

28. Fokkink L G J, De Keizer A and Lyklema J, J Coll Inter Sci., 1989, 127, 116-131.

29. Rodda D P, Johnson B B and Wells J D, J Coll Inter Sci., 1993, 161, 57-62.

30. Bergaoui L, Thèse Doctorat, Université Paris VI, France, 1994.

31. Lagergren S, Handlingar., 1898, 24(4), 1-39.

32. Ho Y S and McKay G, Water Res., 2000, 34(3), 735-742.

33. Freundlich H M F, J Phy Chem., 1906, 57, 385-470.

34. Langmuir I, J Am Chem Soc., 1918, 40, 1361-1403.

35. . Soldo D, Hari R, Sigg L and Behra R, Aquatic Toxicology, 2005, 71, 307-317.

36. Boualia A, Mellah A, Aissaoui T, Menacer K and Silem A, Appl Clay Sci., 1993, 7, 431-445.

37. Rajoriya R K, Prasad B, Mishra I M and Wasewar K L, Chem Biochem Eng Q., 2007, 21(3), 219-226.

38. Bhattacharyya K G and Sarma A, J Environ Manage., 2004, 71(3), 217-229.

39. Crini G, Peindy H N, Gimbert F and Robert C, Sep Purif Technol., 2007, 53, 97-110 